\title{
THE REGIONAL DISTRIBUTION OF FLEAS ON RODENTS.
}

\author{
Bx GEORGE W. McCOY,
}

Passed Assistant Surgeon,

United States Public Health and Marine Hospital Service,

AND MAURICE B. MITZMAIN, B.Sc.,

Assistant, Plague Laboratory, United States Public Health and Marine

Hospital Service, San Francisco, California, U.S.A.

THIS investigation was prompted by the fact that in the study of the lesions of natural plague infection among rats in San Francisco it was found that the anatomical changes produced by the disease were practically identical with those described by the British Plague Commission ${ }^{2}$ in India, except that in San Francisco the location of the bubo in the great majority of cases was in the inguinal region, and practically none of the buboes were found in the cervical region. In India, however, the great majority of the buboes, $743 \%$ in $2956 \mathrm{rats}$, were located in the cervical region, a comparatively small percentage, $14.8 \%$, were in the inguinal region and $10.9 \%$ in the axilla. These figures refer to single buboes only. It was assumed that fleas were responsible for the epizootic among the rats here, as had been shown to be the case in India.

Wherry, Walker and Howell ${ }^{2}$, in a paper on rat plague, as observed in San Francisco, state that the buboes they observed were distributed as follows: one in the cervical region, one. in the axilla, and six in the inguinal region. One of the present writers ${ }^{3}$ reported that in San Francisco, among 29 rats showing single buboes, no case of cervical bubo

1 Journal of Hygiene, Vol. vir. No. 3, p. 386.

2 Journal American Medical Association, April 11, 1908, Vol. L. No. 15.

${ }^{3}$ Public Health Reports, Washington, Vol. xxxir. No. 30, p. 1051. 
had come under observation, while in 21 cases $(72.4 \%)$ the lesion was in the groin, in six cases $(20.4 \%)$ in the axilla and twice $(6.9 \%)$ in the location of the pelvic glands. In the later experience in San Francisco no case of cervical bubo has been observed.

The Indian Plague Commission ${ }^{1}$ found that the situation of the buboes in nearly 200 guinea-pigs experimentally infected with plague by fleas was as follows: $88.9 \%$ were found in the neck, $9.3 \%$ in the groin and $1.8 \%$ in the axilla. These figures are given for those animals having single buboes, constituting $90.5 \%$ of all. The remainder had multiple buboes, i.e. in two or more situations, and in these animals the neck glands were affected in every instance. An effort was made by these observers to ascertain the connection between the situation of plague buboes and the distribution of the fleas on the body of the animal. It had been noted as a common observation that the favourite situation of fleas on the body of animals was the under surface of the neck and beneath the chin, i.e. in the cervical region. An actual count was made on the bodies of 53 live guinea-pigs which were placed singly in a widemouthed, stoppered bottle containing a piece of wool soaked in chloroform, thus stupefying both the animal and the fleas at the same time. The fleas were removed and a careful record taken of the situation in which they were found. A census of the anaesthetized parasites showed $65.3 \%$ takeu on the head and neck, $11.5 \%$ on the forelegs and axillae, $12.9 \%$ on hind legs and groin, and $10.2 \%$ on the trunk of the animal. The commonest situation in which fleas occur on guinea-pigs was thus demonstrated to be the head and neck, the region drained by the cervical lymph glands. In these experiments and observations the species of flea concerned was that common to the rats of India, Loemopsylla cheopis, Rothschild.

The only definite statement we have encountered on the subject of the regional distribution of fleas on rats is that of Pound ${ }^{2}$, who, in speaking of the distribution of fleas on their host, says, "Thus with regard to rats, fleas more commonly occur, when infesting these rodents, about the head and neck than elsewhere."

The Indian Plague Commission makes no statement, so far as we have been able to determine, as to the regional distribution of fleas on rats, but the fact that they found the majority of the buboes in the cervical region leads one to draw the inference that this is the region most infested by fleas in India. As cited above, they demonstrated by

1 Journal of Hygiene, Vol. vi. No. 4, p. 465.

2 Report on Plague in Queensland, 1900-1907, p. 143, B. Burnett Ham. 
actual count that on guinea-pigs the head and neck is the part of the body on which the majority of fleas are found. As will be seen from our tables we have been unable to verify this observation.

It would not be without precedent to find that different species of the same family of insects infest different parts of the body. A very definite regional distribution of certain ectoparasites of man, namely, the lice, has long been recognized. Thus we find Pediculus capitis on the head, Pediculus vestimenti on the general body surface, and Phthirius inguinalis on the pubic region.

In San Francisco it was not practicable to conduct actual flea transmission experiments of plague with either rats or guinea-pigs. In the absence of such experiments it seemed to us that perhaps some clue as to the difference in the location of plague buboes in rats here and in India might be obtained by a careful enumeration of the fleas taken from the various regions of the body of the rats. The work was later extended to include guinea-pigs and squirrels. It should be stated that this work was done after the subsidence of the natural plague among rats in San Francisco and vicinity. The rats have been carefully combed by ourselves or under our immediate supervision, and the figures clearly show that the hind part of the body yields a much larger number of certain species of fleas than is to be obtained from the head and neck or from the forequarters, while another species is confined almost exclusively to the head and neck. We may state that it is the general impression among the attendants who have combed rats here in the routine flea enumeration work, that the majority of the fleas come from the hind regions of the body.,

We have combed a number of squirrels, carefully observing the regions from which the fleas were obtained. It will be seen that here again the common squirrel flea (Ceratophyllus acutus) prefers the hind region of the body, and Hoplopsyllus anomalus, while taken from but one squirrel, showed a marked preference for the hind quarters.

Without insisting upon the significance of these findings we would call attention to the fact that of the four naturally infected plague squirrels reported by Acting Assistant Surgeon Wherry ${ }^{1}$, Public Health and Marine Hospital Service, three had buboes in the inguinal region, and one of these had in addition a bubo in the axilla. The fourth squirrel had no bubo. There was no case of cervical bubo.

A number of fleas have been placed on guinea-pigs and after allowing sufficient time for the insects to orient themselves (from one to five days)

1 Journal of Infectious Diseases, Vol. v. No. 5. 
the animals have been chloroformed and the parasites removed. In the case of $C$. fasciatus and $L$. cheopis the fleas were generally placed on the trunk or on the back of the neck; in the case of $C t$. musculi they were placed on the hind part of the body. In other words, we have placed the fleas in such positions upon the animal that, judging from our experience with rats, it would be necessary for the fleas to move about in order to reach the positions of election for each species.

We have used special care in the guinea-pig experiments as we wished the results to be comparable as far as possible with those of the English workers in India. When we wished to remove the fleas the guinea-pigs were wrapped in a towel saturated with ether, thus stupefying the parasites and preventing any alteration of their position.

In the case of rats the determinations have been made for the most part with animals brought to the laboratory alive, and the fleas removed by one of the procedures to be mentioned later. In a few cases we have put fleas on a rat previously freed of fleas and confined in a mouse jar. On the following day the animal was combed and a note made of the region from which the parasites came. In other cases we have transferred fleas from rats to squirrels and vice versî, and have noted the distribution of the parasites on the new host.

In some cases the rat was injected intraperitoneally with a solution of potassium cyanide. This invariably killed the animal within a minute, and the search for parasites was made at once. This method was intended to prevent any change of position of the fleas due to such struggling as occurred when the animal was coming under the influence of the anaesthetic. Occasionally the animal, as soon as it was dead, was wrapped in filter paper saturated with chloroform ; this effectually prevented any change of position on the part of the parasites. The results obtained in this way did not differ materially from those obtained by the simpler process of chloroforming the rat and the fleas simultaneously, and as the latter method was more convenient we have employed it in the majority of the determinations.

The results obtained by the various methods with each of the species of mammals and of fleas were essentially the same: i.e. the method employed had no influence on the result of the enumeration. Some of these regional determinations were made in Oakland, California, through the courtesy of Passed Assistant Surgeon Carroll Fox.

The average number of fleas on a single rodent was generally so small that, for the purpose of eliminating errors, we have grouped together a number of rodents, including in one group all combed on the same day. 


\begin{tabular}{|c|c|c|c|c|c|c|c|c|c|c|c|c|c|c|c|c|c|c|c|c|}
\hline \multirow[b]{3}{*}{$\begin{array}{l}\text { No. in } \\
\text { Group }\end{array}$} & \multirow[b]{3}{*}{ Host } & \multicolumn{6}{|c|}{ Head and Neck } & \multicolumn{6}{|c|}{ Fore Quarters } & \multicolumn{6}{|c|}{ Hind Quarters } & \multirow[b]{3}{*}{ Total } \\
\hline & & \multicolumn{2}{|c|}{ Fasc. } & \multicolumn{2}{|c|}{ Cheop. } & \multicolumn{2}{|c|}{ Mus. } & \multicolumn{2}{|c|}{ Fase. } & \multicolumn{2}{|c|}{ Cheop. } & \multicolumn{2}{|c|}{$\overbrace{}^{\text {Mus. }}$} & \multicolumn{2}{|c|}{ Fasc. } & \multicolumn{2}{|c|}{ Chrop. } & \multicolumn{2}{|c|}{ Mus. } & \\
\hline & & $\overbrace{M}$ & $\mathrm{~F}$ & $\overparen{\mathbf{M}}$ & $\mathrm{F}$ & $\overparen{\mathbf{M}}$ & $\vec{F}$ & $\overbrace{\mathbf{M}}^{-}$ & $\vec{F}$ & $\overparen{M}$ & $\bar{F}$ & $\overparen{M}$ & $\vec{F}$ & $\overbrace{M}^{M}$ & $F$ & $\overparen{M}$ & $\mathbf{F}$ & $\overparen{M}$ & $\mathbf{F}$ & \\
\hline 13 & $\begin{array}{c}\text { Mus nor- } \\
\text { vegicus }\end{array}$ & - & - & - & - & 2 & 1 & - & - & - & - & - & - & 4 & 12 & - & 1 & - & - & 20 \\
\hline 6 & ", & 1 & 1 & - & - & 1 & 2 & - & 1 & - & - & - & - & - & 8 & 3 & 1 & - & - & 18 \\
\hline 9 &, & - & 2 & - & - & 2 & 3 & 1 & 2 & - & - & 1 & 3 & 4 & 9 & - & 2 & - & - & 29 \\
\hline 8 & 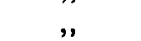 & - & - & 1 & 1 & 2 & 2 & 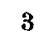 & 2 & - & 1 & - & - & 2 & 12 & 11 & 10 & - & - & 47 \\
\hline 8 & , & - & 1 & - & - & - & - & - & 1 & - & - & - & - & 9 & 10 & - & 1 & - & - & 22 \\
\hline 8 & , & - & $\ldots$ & - & - & 1 & 3 & 2 & 1 & - & - & - & 2 & - & 11 & 2 & 1 & - & - & 23 \\
\hline 9 & & 1 & 4 & 1 & 3 & 1 & 17 & - & 1 & - & - & - & - & 7 & 23 & 2 & 4 & - & - & 64 \\
\hline 10 & , & - & - & 2 & 6 & - & 7 & - & - & 2 & 4 & - & - & 5 & 5 & 10 & 16 & - & 1 & 58 \\
\hline 6 & , & - & - & - & 1 & 2 & 10 & - & - & - & 1 & - & 2 & - & 5 & 6 & 14 & - & - & 41 \\
\hline 10 & , & - & - & - & - & - & - & - & - & - & - & - & 一 & 3 & 6 & - & 6 & - & - & 15 \\
\hline 1 & & - & - & - & - & 4 & 18 & - & - & - & - & - & - & - & - & - & - & - & - & 22 \\
\hline 18 & & - & $\ldots$ & - & - & - & - & - & - & - & 1 & - & 1 & 2 & 2 & 4 & 9 & - & - & 19 \\
\hline 14 & & - & - & - & - & 1 & - & 3 & $\mathbf{5}$ & - & 3 & - & - & 10 & 12 & 1 & 12 & - & - & 47 \\
\hline 19 & , & - & - & - & 1 & - & 2 & - & 1 & - & 1 & - & - & - & 6 & 8 & 18 & - & - & 37 \\
\hline 18 & ", & - & - & - & - & - & - & 2 & 2 & - & 2 & - & - & 2 & 8 & 17 & 26 & - & - & 59 \\
\hline 19 & & - & - & - & - & 1 & - & 3 & 7 & - & - & - & - & 35 & 43 & - & - & - & - & 89 \\
\hline 5 & $48 r$ & - & 1 & - & - & - & 6 & $\rightarrow$ & - & - & - & - & 1 & 3 & 10 & - & - & - & - & 21 \\
\hline 18 & & 2 & 9 & 4 & 12 & 17 & 71 & 14 & 23 & 2 & 13 & 1 & 9 & 86 & 182 & 641 & 121 & - & 1 & \\
\hline & & & & & & & & & & & & & & & & & & & & 331 \\
\hline
\end{tabular}

Rats killed by the intraperitoneal injection of potassium cyanide.

\begin{tabular}{|c|c|c|c|c|c|c|c|c|c|c|c|c|c|c|c|c|c|c|c|c|}
\hline 6 & $\begin{array}{c}\text { Mus nor. } \\
\text { vegicus }\end{array}$ & - & - & - & - & 2 & 3 & - & - & - & - & - & 1 & 1 & 4 & - & - & - & - & 11 \\
\hline 15 & ," & - & - & 1 & - & 3 & 6 & - & 1 & - & 1 & 1 & 1 & 4 & 13 & 11 & 8 & - & - & 50 \\
\hline 7 & " & - & - & - & - & 7 & 21 & - & - & - & - & 1 & 6 & 1 & 4 & 1 & 1 & - & - & 42 \\
\hline 9 & ", & - & - & - & - & 3 & 11 & - & - & 1 & 4 & - & 1 & 1 & 6 & 5 & 8 & - & - & 40 \\
\hline 37 & $\bar{y}$ & - & - & 1 & - & 15 & 41 & - & 1 & 1 & 5 & 2 & 9 & 7 & 27 & 17 & 17 & - & - & \\
\hline
\end{tabular}

Fleas placed on rats confined in mouse jar.

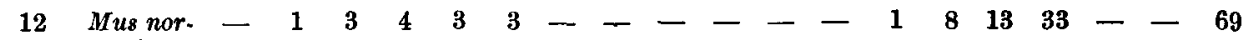
vegicus

Total both sexes $\underbrace{=}_{1} \underbrace{=}_{7} \underbrace{2}_{46}$


For the purpose of these determinations that part of the animal lying in front of the fore legs was called "head and neck." The "hind quarters" included everything posterior to the middle of the trunk, and the parts lying between this and the "head and neck" was called the "fore quarters."

A summary of the three tables, including a total of 230 rats, shows the percentages of species of fleas as follows :

$\begin{array}{lccc} & \text { Fasciatus } & \text { Cheopis } & \text { Musculi } \\ \text { Head and Neck } & 3 \cdot 3 \% & 7 \cdot 7 \% & 87 \cdot 2 \% \\ \text { Fore Quarters } & 10 \cdot 5 & 6 \cdot 8 & 12 \cdot 2 \\ \text { Hind Quarters } & 86 \cdot 2 & 85 \cdot 5 & \cdot 6\end{array}$

Distribution of squirrel fleas (Ceratophyllus acutus) on rats.

\begin{tabular}{|c|c|c|c|c|c|c|}
\hline \multirow{2}{*}{$\begin{array}{l}\text { No. in } \\
\text { Group }\end{array}$} & \multirow[b]{2}{*}{ Host } & \multicolumn{2}{|c|}{$\begin{array}{c}\text { Fore Quarters } \\
\text { C. acutus }\end{array}$} & \multicolumn{2}{|c|}{$\begin{array}{c}\text { Hind Quarters } \\
\text { C. acutus }\end{array}$} & \multirow[b]{2}{*}{ Total } \\
\hline & & $\mathbf{M}$ & $\mathbf{F}$ & $\bar{M}$ & F & \\
\hline 9 & Mus norvegicus & 1 & 1 & 18 & 16 & 38 \\
\hline \multicolumn{2}{|c|}{ Total both sexes } & \multicolumn{2}{|c|}{2} & \multicolumn{2}{|c|}{34} & \\
\hline \multicolumn{2}{|c|}{ Percentage } & \multicolumn{2}{|c|}{6} & \multicolumn{2}{|c|}{$9 \overline{4}$} & \\
\hline
\end{tabular}

Distribution of squirrel fleas (Ceratophyllus acutus and Hoplopsyllus anomalus) on squirrels (Citellus beecheyi).

\begin{tabular}{|c|c|c|c|c|c|c|c|c|c|c|c|c|c|c|}
\hline \multirow{3}{*}{$\begin{array}{l}\text { No. in } \\
\text { Group }\end{array}$} & \multirow[b]{3}{*}{ Host } & \multicolumn{4}{|c|}{ Head and Netk } & \multicolumn{4}{|c|}{ Fore Quarters } & \multicolumn{4}{|c|}{ Hind Quarters } & \multirow{3}{*}{ Total } \\
\hline & & \multicolumn{2}{|c|}{ c. acutus } & \multicolumn{2}{|c|}{ Anomalus } & \multicolumn{2}{|c|}{ C.acutus } & \multicolumn{2}{|c|}{ Anomalus } & \multicolumn{2}{|c|}{ C. acutus } & \multicolumn{2}{|c|}{ Anomalus } & \\
\hline & & $\overline{\mathbf{M}}^{-1}$ & $\vec{F}$ & $\bar{M}$ & $\widehat{F}$ & $\bar{M}$ & $\vec{F}$ & $\tau_{M}$ & $\vec{F}$ & $\bar{M}$ & $\widehat{F}$ & $\vec{M}$ & $\bar{F}$ & \\
\hline 11 & C. beecheyi & 19 & 16 & - & - & 38 & 58 & - & - & 93 & 118 & - & - & 342 \\
\hline 8 & , & 5 & - & - & - & 37 & 44 & 2 & - & 42 & 31 & - & - & 161 \\
\hline 6 & , & 14 & 16 & 一 & - & 15 & 26 & - & 4 & 33 & 39 & 8 & 23 & 178 \\
\hline 25 & & 33 & 37 & - & - & 90 & 128 & 2 & 4 & 168 & 188 & 8 & 23 & \\
\hline otal & DEASD & & & & & & & & & & & & & 681 \\
\hline
\end{tabular}

From this we find that the percentages are as follows:

$\begin{array}{lcc} & \text { C. acutus } & \text { H. anomalus } \\ \text { Head and Neck } & 10 \cdot 9 \% & 00 \cdot 0 \% \\ \text { Fore Quarters } & \mathbf{3 3} \% 8 & 16 \cdot 2 \\ \text { Hind Quarters } & 55 \cdot 3 & \mathbf{8 3 \cdot 8}\end{array}$


Distribution of rat fleas on guinea-pigs.

GroUp 1. Ceratophyllus fasciatus.

\begin{tabular}{|c|c|c|c|c|c|c|c|c|c|c|c|c|c|c|c|c|c|c|c|}
\hline \multirow{3}{*}{$\begin{array}{l}\text { No. of guinea- } \\
\text { pigs in group }\end{array}$} & \multicolumn{6}{|c|}{ Head and Neck } & \multicolumn{6}{|c|}{ Fore Quarters } & \multicolumn{6}{|c|}{ Hind Quarters } & \multirow[b]{3}{*}{ Total } \\
\hline & \multicolumn{2}{|c|}{ Fasc. } & \multicolumn{2}{|c|}{ Cheop. } & \multicolumn{2}{|c|}{$\overbrace{}^{M u s .}$} & \multicolumn{2}{|c|}{ Fasc. } & \multicolumn{2}{|c|}{ Cheop. } & \multicolumn{2}{|c|}{ 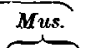 } & \multicolumn{2}{|c|}{ Fasc. } & \multicolumn{2}{|c|}{ Cheop. } & \multicolumn{2}{|c|}{$\overbrace{\text { Mus. }}^{\text {M }}$} & \\
\hline & $\overparen{\mathbf{M}}$ & $\mathbf{F}$ & $\overparen{M}$ & $F$ & $\overparen{\mathbf{M}}$ & $\vec{F}$ & $\overparen{\mathbf{M}}$ & $\mathbf{F}$ & $\overparen{\mathbf{M}}$ & $\vec{F}$ & $\overparen{M}$ & $F$ & $\overparen{M}$ & $\bar{F}$ & $\overparen{M}$ & $\mathbf{F}$ & $\widetilde{\mathbf{M}}$ & $\mathbf{F}$ & \\
\hline 9 & 1 & 2 & $一$ & - & - & - & 2 & 6 & - & - & - & - & 11 & 37 & - & - & - & - & - \\
\hline & & 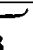 & & & & & & & & & & & 4 & & & & & & 59 \\
\hline
\end{tabular}

GrodP II.'Loemopsylla cheopis.

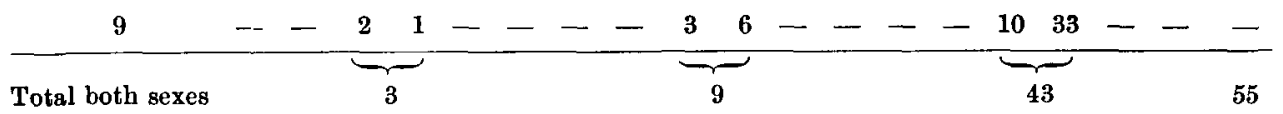

Grotp 3. Ceratophyllus fasciatus, Loemopsylla cheopis and Ctenopsyllus musculi.

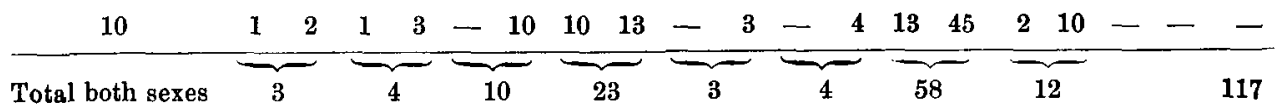

Summary of three groups.

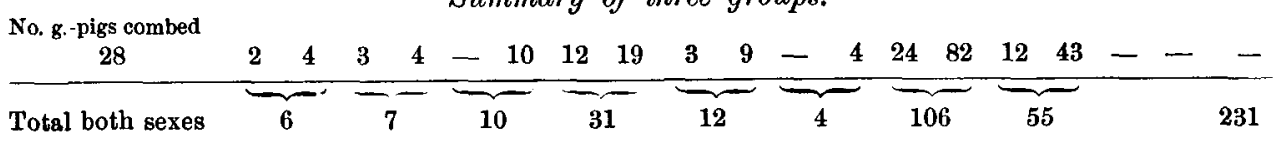

These figures yield the following percentages:

$\begin{array}{lccc} & \text { C. fasciatus } & \text { L. cheopis } & \text { Ct. musculi } \\ \text { Head and Neck } & 4 \% & 10 \% & 72 \% \\ \text { Fore Quarters } & 22 & 16 & 28 \\ \text { Hind Quarters } & 74 & 74 & 0\end{array}$

\section{Summary and Conclusion.}

It would appear from the data presented that the favourite location for the common rat lleas of this vicinity, Ceratophyllus fasciatus, Bosc., and Loemopsylla cheopis, Roth., is about the hind quarters of the rat, while Ctenopsyllus musculi (Dugès), Wagner, prefers the region of the head and neck.

The same regional distribution of rat fleas was found in the case of the guinea-pigs. 
Squirrel fleas are most numerous on the hind quarters.

These observations, while they are not to be insisted upon as throwing any special light upon the regional distribution of buboes in naturally infected plague rats, are of particular interest in showing the very constant preference of $C t$. musculi for the region of the head and neck.

In regard to the other species of fleas it should be borne in mind that the skin areas are not of equal dimensions; that of the head aud neck being smallest; that of the hind quarters being the largest; and the skin area of the fore quarters being between these in size. 